\title{
The ocular side effects of vigabatrin (Sabril): information and guidance for screening
}

Eye (2008) 22, 1097-1098; doi:10.1038/eye.2008.139; published online 23 May 2008

\section{Background}

Vigabatrin (Sabril) is an antiepileptic drug indicated for the treatment of partial epilepsy, which is only licensed as first line/ monotherapy for the treatment of infantile spasms (West's syndrome). In 1997, three cases of severe, symptomatic, persistent visual field constriction associated with vigabatrin treatment were described. ${ }^{1}$ This led to the recommendation that vigabatrin therapy should only be initiated by an epilepsy specialist and in clinical situations where all other antiepileptic therapies had not been effective or tolerated. A NICE Technology Appraisal in 2004 found that there was no convincing evidence for superiority of seizure control by vigabatrin compared with alternative therapies in either partial seizures or West's syndrome. However, the risk of visual field constriction attributable to vigabatrin (VAVFC) must be balanced against the adverse effects of alternative therapies, and of uncontrolled epilepsy, and vigabatrin therapy remains an important option in this group.

Overall, it appears that the use of vigabatrin as an antiepileptic drug is declining. ${ }^{2}$

\section{Clinical features}

Patients with VAVFC are usually asymptomatic of the field loss unless the defect encroaches within the central field. ${ }^{3}$ Visual field loss can exist in the absence of any demonstrable fundal pathology observed clinically. However, optic nerve head pallor and retinal nerve fibre layer atrophy ${ }^{4}$ have been demonstrated in subjects taking vigabatrin. VAVFC (best detected by static perimetry in subjects over 9 years of age)
MJ Hawker and NJ Astbury

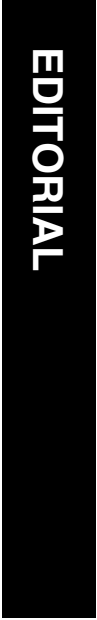

is characteristically bilateral, concentric, and predominantly nasal, and has an estimated prevalence of $30-40 \% .^{5-7}$ In a minority of patients, VAVFC has been so severe that it limited their ability to perform a variety of activities of daily living.

\section{Electrophysiology}

Electrophysiological testing may reveal a normal VEP response, ERG abnormalities (increased photopic $\beta$-wave latency, reduced $\beta$-wave amplitude, and reduced oscillatory potentials) $)^{8,9}$ and a reduced Arden Index on EOG testing. ${ }^{5,8,10}$ Field-specific VEP responses have shown promise in detecting VAVFC in subjects unable to produce reliable perimetry such as children. ${ }^{11}$

\section{Risk factors}

Men on vigabatrin have an increased risk of developing VAVFC of approximately twofold compared with women. ${ }^{7,8}$

The prevalence of VAVFC rises steeply at cumulative doses between 1 and $3 \mathrm{~kg}^{12}$ with a cumulative risk plateau at $5 \mathrm{~kg} .{ }^{13}$ The majority of cases occur after a year of treatment.

Children present a particular problem as accurate assessment of visual impairment is difficult, but the prevalence of VAVFC in paediatric patients has been estimated to be $29 \%{ }^{13}$

\section{Prognosis}

The vast majority of studies indicate that VAVFC does not reverse on cessation of the drug, and may worsen with continued use. ${ }^{14}$ Progression of VAVFC after stopping vigabatrin has not been reported to date.
Department of Ophthalmology, Norfolk and Norwich University NHS Trust, Norwich, Norfolk, UK

Correspondence:

MJ Hawker,

Department of

Ophthalmology, Norfolk and Norwich University NHS Trust, Colney Lane, Norwich, Norfolk NR4 7UY, UK

Tel: 01603286 286; Fax: 01603286286. E-mail: matthawker@ doctors.org.uk 


\section{Screening recommendations}

- A baseline visual field should be obtained before starting treatment.

- Visual field examination should be undertaken with Humphrey 120 point, Octopus 07, or Goldmann perimetry (III4e and I4e or I2e stimuli, as appropriate).

- Perimetry should be repeated every 6 months for 5 years. It can then be extended to annually in patients who have no defect detected.

- If VAVFC is detected, it is advisable to conduct a confirmatory field test within 1 month before considering cessation of vigabatrin.

- If the drug is discontinued, perimetry should be repeated at a future date to monitor the field loss.

In subjects unable to perform perimetry (typically children under 9 years and approximately $20 \%$ of adults with epilepsy ${ }^{9}$ ), field-specific VEPs may detect an absent peripheral response but the diagnostic accuracy of field-specific VEP testing requires further validation.

\section{Discussion with patients and carers}

- It is the responsibility of the prescribing doctor to discuss with the patient, or the patient's relatives or carers, the risks of VAVFC.

- As the degree of field loss may be severe enough to limit driving and even daily activities, the potential risk needs to be assessed against the potential benefit of seizure control.

- Patients should be alerted to report any abnormalities in their vision, and must be informed of any abnormalities in visual field tests.

- Patients should be advised that VAVFC can worsen if the drug is continued, although it may remain static, particularly if the duration of treatment is greater than 5 years or the cumulative dose is greater than $5 \mathrm{~kg}$.

\section{Conclusions}

There are still many unanswered questions concerning the relation between vigabatrin and visual field defects. Evaluation of the clinical situation is difficult when it comes to assessing the potential risk to the patient, particularly where children are concerned. It is a matter for the prescribing paediatrician or neurologist to weigh up the dangers of potential side effects against seizure control and to instigate screening for VAVFC. Accurate visual field monitoring will enable a more informed decision on whether to initiate or continue treatment with vigabatrin.

The unabridged guideline is available at http:/ / www.rcophth.ac.uk/docs/publications/publishedguidelines/Vigabatrin_Guidelines_March_2008.pdf

\section{References}

1 Eke T, Talbot JF, Lawden MC. Severe persistent visual field constriction associated with vigabatrin. BMJ 1997; 314(7075): 180-181.

2 Ackers R, Murray ML, Besag FM, Wong IC. Prioritizing children's medicines for research: a pharmacoepidemiological study of antiepileptic drugs. $\mathrm{Br} \mathrm{J}$ Clin Pharmacol 2007; 63(6): 689-697.

3 Daneshvar H, Racette L, Coupland SG, Kertes PJ, Guberman A, Zackon D. Symptomatic and asymptomatic visual loss in patients taking vigabatrin. Ophthalmology 1999; 106(9): 1792-1798.

4 Wild JM, Robson CR, Jones AL, Cunliffe IA, Smith PE. Detecting vigabatrin toxicity by imaging of the retinal nerve fiber layer. Invest Ophthalmol Vis Sci 2006; 47(3): 917-924.

5 Lawden MC, Eke T, Degg C, Harding GF, Wild JM. Visual field defects associated with vigabatrin therapy. J Neurol Neurosurg Psychiatry 1999; 67(6): 716-722.

6 Miller NR, Johnson MA, Paul SR, Girkin CA, Perry JD, Endres $\mathrm{M}$ et al. Visual dysfunction in patients receiving vigabatrin: clinical and electrophysiologic findings. Neurology 1999; 53(9): 2082-2087.

7 Wild JM, Ahn HS, Baulac M, Bursztyn J, Chiron C, Gandolfo E et al. Vigabatrin and epilepsy: lessons learned. Epilepsia 2007; 48(7): 1318-1327.

8 Kalviainen R, Nousiainen I. Visual field defects with vigabatrin: epidemiology and therapeutic implications. CNS Drugs 2001; 15(3): 217-230.

9 Harding GF, Wild JM, Robertson KA, Rietbrock S, Martinez C. Separating the retinal electrophysiologic effects of vigabatrin: treatment versus field loss. Neurology 2000; 55(3): 347-352.

10 Harding GF, Robertson KA, Edson AS, Barnes P, Wild J. Visual electrophysiological effect of a GABA transaminase blocker. Doc Ophthalmol 1998; 97(2): 179-188.

11 Harding GF, Spencer EL, Wild JM, Conway M, Bohn RL. Field-specific visual-evoked potentials: identifying field defects in vigabatrin-treated children. Neurology 2002; 58(8): 1261-1265.

12 Malmgren K, Ben-Menachem E, Frisen L. Vigabatrin visual toxicity: evolution and dose dependence. Epilepsia 2001; 42(5): 609-615.

13 Lawden MC. Vigabatrin-associated visual field constriction: a review. Optometry Pract 2006; 7: 1-14.

14 Hardus P, Verduin WM, Postma G, Stilma JS, Berendschot TT, van Veelen CW. Long term changes in the visual fields of patients with temporal lobe epilepsy using vigabatrin. Br J Ophthalmol 2000; 84(7): 788-790. 